\title{
Optimizing prostate cancer accumulating model: combined PI-RADS v2 with prostate specific antigen and its derivative data
}

\author{
Yuan-Fei Lu', Qian Zhang ${ }^{1}$, Wei-Gen Yao ${ }^{2}$, Hai-Yan Chen ${ }^{1}$, Jie-Yu Chen ${ }^{1}$, Cong-Cong Xu ${ }^{3}$ and Ri-Sheng Yu ${ }^{1 *}$ (D)
}

\begin{abstract}
Background: To establish a new accumulating model to enhance the accuracy of prostate cancer (PCa) diagnosis by incorporating prostate-specific antigen (PSA) and its derivative data into the Prostate Imaging-Reporting and Data System version 2 (PI-RADS V2).
\end{abstract}

Methods: A total of 357 patients who underwent prostate biopsy between January 2014 and December 2017 were included in this study. All patients had 3.0 T multiparametric magnetic resonance imaging (MRI) and complete laboratory examinations. PI-RADS V2 was used to assess the imaging. PSA, PSA density (PSAD), the free/total PSA ratio (f/t PSA) and the Gleason score (GS) were classified into four-tiered levels, and optimal weights were pursued on these managed levels to build a PCa accumulating model. A receiver operating characteristic curve was generated. Results: In all, 174 patients (48.7\%) had benign prostatic hyperplasia, and 183 (51.3\%) had PCa, among whom 149 (81. $4 \%, 149 / 183$ ) had clinically significant PCa. The established model 6 (PI-RADS v2 + level of PSAD + level of f/t PSA+ level of PSA) had a sensitivity and specificity of 81.4 and $84.5 \%$, respectively, at the cut-off point of 11 in PCa diagnosis. Correspondingly, at the 12 cut-off point, the sensitivity and specificity were 87.7 and $83.0 \%$, respectively, in diagnosing clinically significant PCa. The score of the new accumulating system was significantly different among the defined GS groups $(p<0.001)$. The mean values and 95\% confidence intervals for GS 1-4 groups were 10.20 (9.63-10.40), 12.03 (11. 19-12.87), 14.12 (13.60-14.64) and 15.44 (15.09-15.79).

Conclusions: A new PCa accumulating model may be useful in improving the accuracy of the primary diagnosis of $\mathrm{PCa}$ and helpful in the clinical decision to perform a biopsy when MRI results are negative.

Keywords: Prostate cancer, MRI, Prostate-specific antigen, Model

\section{Background}

Prostate cancer $(\mathrm{PCa})$ is the most common cancer in men in Western countries [1], and the number of males diagnosed with $\mathrm{PCa}$ in Asia is increasing dramatically [2]. In 2014, the Prostate Imaging-Reporting and Data System version 2 (PI-RADS v2) was published to simplify and standardize the terminology and content of radiology reports [3, 4]. The system classifies all imaging characters into 5 points to diagnose $\mathrm{PCa}$, from 1 point, which has a very low probability, to 5 points, which has a very high probability [3]. However, the PI-RADS score

\footnotetext{
* Correspondence: risheng-yu@zju.edu.cn

${ }^{1}$ Department of Radiology, Second Affiliated Hospital, School of Medicine, Zhejiang University, 88 Jie-Fang Road, Zhejiang 310009, Hangzhou, China Full list of author information is available at the end of the article
}

is not perfect because its negative predictive value (NPV) is unstable [5]. Hence, coordinating imaging with other laboratory data is worth considering.

Prostate-specific antigen (PSA) screening is widely used to assess $\mathrm{PCa}$, despite its false-positive rate and its overtreatment because of its inferior accuracy. The cut-off point of $4 \mathrm{ng} / \mathrm{mL}$ is not sufficient to evaluate the risk of PCa [6]. However, it is still the first index used to detect the presence of PCa [7]. PSA density (PSAD) and the free/total PSA ratio (f/t PSA), clinical statistics available from PSA, are considered more sensitive in predicting $\mathrm{PCa}[8,9]$.

To date, few studies have combined PI-RADS v2 with clinical data to improve PCa detection [10, 11]. Washino $\mathrm{S}$ et al. combined PSAD as the only independent variable 
and used the detection rate as the sole evaluation index [10]. To estimate PCa more comprehensively, our study attempts to establish a new model with additional clinical variables by quantifying those results and thus providing the clinician with a convenient and simple model to diagnose $\mathrm{PCa}$ and even its biological malignancy.

Imitating PI-RADS v2, our study stratified PSA, PSAD and $f / t$ PSA and gave each level a point. Then, a simple, leaner accumulating model was built, aiming at utilizing available data thoroughly, improving the diagnostic accuracy of PCa and ultimately decreasing the number of unnecessary biopsies.

\section{Methods}

\section{Patient population}

This retrospective study was performed at our institution. Institutional review board approval and informed consent were obtained. Related data of patients who had standard prostate magnetic resonance imaging (MRI) examinations for any reason between January 2014 and December 2017 were collected, including imaging results, the results of biochemical examinations, and pathological reports. The inclusion criteria were as follows: (i) all patients underwent standardized prostate multiparametric MRI (mpMRI) before drug, biopsy or surgical therapy, (ii) serum examination was performed before treatment, and (iii) transrectal ultrasonography and 12-core prostate biopsy with pathological results were performed in the next 2 weeks after mpMRI. Of the 1039 patients who had undergone prostate mpMRI, 357 patients were eligible for the study. Clinically significant $\mathrm{PCa}$ (CS PCa) was indicated by a maximum cancer core length $\geq 4 \mathrm{~mm}$ and/or a Gleason grade $\geq 3+4$ [12]

\section{MRI}

All patients underwent MRI examinations on 3.0 T GE equipment (DISCOVER MR750 GEHCGEHC) using a multichannel vitro coil. Turbo spin-echo T2-weighted imaging (repetition time msec/echo time msec, 42914569/95.9-101.2; section thickness, 3-4 mm; intersection gap, $0 \mathrm{~mm}$; field of view, $200 \times 200 \mathrm{~mm}$; matrix, $352 \times 352$ ), diffusion-weighted imaging (DWI, repetition time msec/echo time msec, 4000/57-59; section thickness, 3-4 mm; intersection gap, $0 \mathrm{~mm}$; field of view, $370 \times 370 \mathrm{~mm}$; matrix, $128 \times 160$ ), and apparent diffusion coefficient and dynamic contrast-enhanced imaging (repetition time msec/echo time msec, 4.3/1.9-2.0; section thickness, 3-4 mm; intersection gap, $0 \mathrm{~mm}$; field of view, $320 \times 320 \mathrm{~mm}$; matrix, $320 \times 224$; dose $0.1 \mathrm{mmol} /$ $\mathrm{kg}$ standard gadolinium-based contrast agent; injection rate: $2-3 \mathrm{cc} / \mathrm{sec}$ ) were performed. The $\mathrm{b}$ value of DWI was $1500 \mathrm{~s} / \mathrm{mm}^{2}$. The imaging was read by two independent radiologists who were trained through the PI-RADS v2 criterion and blinded to clinical data to decrease bias in reading the results. If the conclusions were not concordant, the final score was determined by a senior radiologist who specialized in abdominal radiology for more than 30 years. T2-weighted imaging and DWI were the dominant determining sequences for the central and peripheral zones, respectively. Prostate volume was measured in T1-weighted imaging, and a formula multiplying length by width by height by $0.52^{3}$ was applied.

\section{Pathology}

The prostate biopsies were taken transrectally using an automatic biopsy gun and a $12+\mathrm{X}-\mathrm{G}$ needle under ultrasound guidance (six in the peripheral zone, six in the transitional zone, $\mathrm{X}$ in the suspicious zone). TRUS-guided biopsy was combined with TRUS-guided targeted biopsy and cognitive MRI fusion-guided targeted biopsy. Prostate surgery included radical prostatectomy and transurethral resection of the prostate. The specimens that were obtained as described above were assessed by experienced pathologists.

\section{Statistical analyses}

Clinical data included PSA, f/t PSA and PSAD. The classification of these variables referred to published papers that were based on large populations. PSA values were split into 4 levels: the cut-off points were 4, 10 and 20 $\mathrm{ng} / \mathrm{mL}$ [13]. This study defined PSA $<4 \mathrm{ng} / \mathrm{mL}$ as level $1,4-10 \mathrm{ng} / \mathrm{mL}$ as level $2,10-20 \mathrm{ng} / \mathrm{mL}$ as level 3 and PSA greater than $20 \mathrm{ng} / \mathrm{mL}$ as level 4. Likewise, 0.1, 0.19 and $0.23 \mathrm{ng} / \mathrm{mL} / \mathrm{mL}$ of PSAD were used to stratify patients into 4 planes $[14,15]$. From the lower to upper layer, levels 1 to 4 were set for each plane. For f/t PSA, $0.14,0.18$, and 0.24 were defined as the cut-off scores [16]. An explicit figure was not given if PSA was greater than $1000 \mathrm{ng} / \mathrm{mL}$, and we defined the f/t PSA as 0.001 in these situations. In contrast, level 1 was assigned for $\mathrm{f} / \mathrm{t}$ PSA more than 0.24 , and levels 2,3 , and 4 were listed in descending order by $\mathrm{f} / \mathrm{t}$ PSA. Regarding the pathological results, the Gleason score (GS) was in accordance with the malignancy of the lesion [17]. According to the prognosis, GS was divided into four-tiered groupings: < 6 was defined as group 1, 6 as group 2, 7 as group 3, and 8 to 10 as group 4 [18-22].

Imaging data were combined with serum results to build accumulating models. Optimal weights of each level of quota were found to obtain the most satisfactory model. The following equations were derived based on the logistic regression equation and correlation coefficient. Thus, thirteen models were established to mutually compare to find a simple and satisfactory $\mathrm{PCa}$ accumulating system as follows:

model 1: PI-RADS v2 + level of PSAD

model 2: PI-RADS v2 + level of $\mathrm{f} / \mathrm{t}$ PSA 
model 3: PI-RADS v2 + level of PSA

model 4: PI-RADS v2 + level of PSAD + level of $\mathrm{f} / \mathrm{t}$ PSA

model 5: PI-RADS v2 + level of PSAD + level of PSA

model 6: PI-RADS v2 + level of PSAD + level of $f / t$

PSA + level of PSA

model 7: $2 \times$ PI-RADS v2 $+3 \times$ level of PSAD

model 8: $2 \times$ PI-RADS v2 $+3 \times$ level of PSAD + level of f/t PSA

model 9: $2 \times$ PI-RADS v2 $+3 \times$ level of PSAD + level of

PSA

model 10: $2 \times$ PI-RADS v2 $+3 \times$ level of PSAD + level

of $\mathrm{f} / \mathrm{t}$ PSA+ level of PSA.

model 11: $2 \times$ PI-RADS v2 $+2 \times$ level of PSAD + level of $\mathrm{f} / \mathrm{t}$ PSA

model 12: $2 \times$ PI-RADS v2 $+2 \times$ level of PSAD + level of PSA

model 13: $2 \times$ PI-RADS v2 $+2 \times$ level of PSAD + level of $\mathrm{f} / \mathrm{t}$ PSA + level of PSA.

The best-fit receiver operating characteristics of thirteen models were calculated. Univariate and multivariate logistic regression analyses were performed. The relationship between the scores of the accumulating model and GS was analysed by one-way ANOVA. All data were analysed in SPSS 23.0 , and $p<0.05$ indicated statistical significance.

\section{Results}

Of the 357 patients involved in the study, 48.7\% (174/ 357 ) had benign prostatic hyperplasia (group 1), $51.3 \%$ $(183 / 357)$ were diagnosed with PCa, and 45.7\% (163/ 357) had CS PCa. Among patients with PCa, 18.6\% (34/ 183) had GS $3+3$ PCa (group 2), 40.4\% (74/183) had GS 7 (group 3), and 41.0\% (75/183) had GS 8-10 (group 4). Of GS $3+3,14$ had a maximum cancer core length $\geq 4$ $\mathrm{mm}$. The patient characteristics are presented in Table 1. The medians and interquartile ranges of age, PSA, $\mathrm{f} / \mathrm{t}$ PSA and PSAD were 68 (63-74), 11.06 (6.79-21.34), $0.13(0.08-0.19)$ and $0.24(0.15-0.56)$, respectively. In nonparametric correlations, the Kendall's tau_b coefficients were as follows: between PSAD and f/t PSA, 0.422; between PSAD and PSA, 0.626; and between PSA and $f / t$ PSA, 0.253 . The variable levels of PSA, PSAD, $f / t$ PSA and PI-RASD v2 were clearly related to the presence of PCa and CS PCa, especially PI-RADS v2 and the level of PSAD. The levels of PSA and $f / t$ PSA were rejected in the $\mathrm{PCa}$ diagnosis in the logistic regression (Table 2). In a head-to-head-comparison between each category, the performances of levels of each variable are presented in Table 2.

The receiver operating characteristic curves of models 1 to 13 were calculated (Fig. 1a, b). To diagnose PCa, it appeared that the area under the curve increased with additional clinical variables added, with PI-RADS v2 as
Table 1 The patients' characteristics

\begin{tabular}{ll}
\hline Variable & Vaule \\
\hline & median \\
age, years & 68 \\
PSA ng/mL & 11.06 \\
f/t PSA & 0.13 \\
PSAD ng/mL/mL & 0.24 \\
Gleason score & frequency \\
BPH & 174 \\
score 6 & 34 \\
score 7 & 74 \\
score 8 & 47 \\
score 9 & 22 \\
score 10 & 6 \\
PI-RADSv2 score & 6 \\
1-2 & 154 \\
3 & 35 \\
$4-5$ & 168 \\
\hline
\end{tabular}

IQR interquartile range, $m p M R I$ multiparametric magnetic resonance imaging, PI-RADS V2 The Prostate Imaging- Reporting and Data System Version 2, BPH benign prostatic hyperplasia

the base. All models had more capacity to distinguish the absence or presence of CS PCa compared to PCa diagnosis. The characteristics of the 13 models are presented in Table 3.

As shown in Fig. 1a, models 6 and 13 were good. When scores of model $6 \geq 11$ were considered positive, the sensitivity, specificity, positive predictive value (PPV) and negative predictive value (NPV) for PCa were 0.814 (149/183), 0.845 (147/174), 0.847 (149/176) and 0.812 $(147 / 181)$, respectively, compared to 0.754 (138/183), 0.828 (144/174), 0.821 (138/168) and 0.762 (144/189), respectively, for PI-RDAS v2. For CS PCa assessment, the cut-off point was 12 , with sensitivity, specificity, PPV and NPV of 0.877 (143/163), 0.830 (161/194), 0.813 $(143 / 176)$ and $0.890(161 / 181)$, respectively, compared to 0.843 (136/163), 0.830 (161/194), 0.805 (136/169) and 0.856 (161/188), respectively, for PI-RDAS v2. In other words, among the 189 people with PI-RADS v2 scores of $1-3,23.8 \%(45 / 189)$ PCa patients were missed, and $17.2 \%$ (30/168 PI-RADS v2 score 4-5) were false positives and underwent unnecessary biopsy. In model 6, $18.8 \%$ (34/181) were missed, and $15.3 \%$ (27/176) were false positives. In total, 11 patients were correctly diagnosed, and 3 were prevented from incorrect diagnosis when PI-RADS v2 was incorrect.

Model 13 showed a stronger capacity in diagnosing PCa. At a cut-off point of 18 , the sensitivity, specificity, PPV and NPV were 0.847 (155/183), 0.845 (147/174), $0.852(155 / 182)$ and $0.84(147 / 175)$, respectively. To assess CS PCa, the cut-off point was 18 , with sensitivity, 
Table 2 Univariate and multivariate logistic regression analyses to detect PCa and CS PCa

\begin{tabular}{|c|c|c|c|c|c|c|c|c|c|c|c|c|c|c|c|c|}
\hline & \multicolumn{8}{|l|}{$\mathrm{PCa}$} & \multicolumn{8}{|c|}{ CS PCa } \\
\hline & \multicolumn{4}{|c|}{ univariate analysis } & \multicolumn{4}{|c|}{ multivariate analysis } & \multicolumn{4}{|c|}{ univariate analysis } & \multicolumn{4}{|c|}{ multivariate analysis } \\
\hline & \multirow[t]{2}{*}{ OR } & \multicolumn{2}{|c|}{$\begin{array}{l}95 \% \text { Confidence } \\
\text { Interval }\end{array}$} & \multirow[t]{2}{*}{ P } & \multirow[t]{2}{*}{$\mathrm{OR}$} & \multicolumn{2}{|c|}{$\begin{array}{l}95 \% \text { Confidence } \\
\text { Interval }\end{array}$} & \multirow[t]{2}{*}{ P } & \multirow[t]{2}{*}{ OR } & \multicolumn{2}{|c|}{$\begin{array}{l}\text { 95\% Confidence } \\
\text { Interval }\end{array}$} & \multirow[t]{2}{*}{$P$} & \multirow[t]{2}{*}{$\mathrm{OR}$} & \multicolumn{2}{|c|}{$\begin{array}{l}95 \% \text { Confidence } \\
\text { Interval }\end{array}$} & \multirow[t]{2}{*}{$P$} \\
\hline & & Lower & Upper & & & Lower & Upper & & & Lower & Upper & & & Lower & Upper & \\
\hline \multicolumn{17}{|l|}{ PI-RADS v2 } \\
\hline $1-2$ & - & - & - & - & - & - & - & - & - & - & - & - & - & - & - & - \\
\hline 3 & 1.36 & 0.596 & 3.102 & 0.465 & 1.214 & 0.474 & 3.113 & 0.686 & 1.241 & 0.462 & 3.335 & 0.668 & 1.051 & 0.337 & 3.272 & 0.932 \\
\hline 4 & 3.024 & 2.275 & 4.019 & $<0.001$ & 2.398 & 1.745 & 3.296 & $<0.001$ & 3.775 & 2.78 & 5.126 & $<0.001$ & 3.29 & 2.316 & 4.674 & $<0.001$ \\
\hline 5 & 5.854 & 2.993 & 11.448 & $<0.001$ & 4.352 & 2.148 & 8.817 & $<0.001$ & 7.074 & 3.599 & 13.905 & $<0.001$ & 5.241 & 2.54 & 10.811 & $<0.001$ \\
\hline \multicolumn{17}{|c|}{ PSAD (ng/mL/mL) } \\
\hline$<0.1$ & - & - & - & - & - & - & - & - & - & - & - & - & - & - & - & - \\
\hline $0.1-0.19$ & 4.234 & 1.191 & 15.051 & 0.026 & 3.505 & 0.723 & 16.982 & 0.119 & 3.8 & 0.826 & 17.482 & 0.086 & 2.171 & 0.307 & 15.373 & 0.428 \\
\hline $0.19-0.23$ & 2.099 & 1.087 & 4.053 & 0.027 & 3.237 & 1.026 & 10.213 & 0.045 & 2.132 & 0.974 & 4.666 & 0.058 & 4.787 & 0.974 & 23.536 & 0.054 \\
\hline$\geq 0.23$ & 3.97 & 2.622 & 6.01 & $<0.001$ & 1.904 & 1.063 & 3.411 & 0.03 & 4.185 & 2.564 & 6.83 & $<0.001$ & 2.087 & 1.089 & 4 & 0.027 \\
\hline \multicolumn{17}{|l|}{ f/t PSA } \\
\hline$\geq 0.24$ & - & - & - & - & - & - & - & - & - & - & - & - & - & - & - & - \\
\hline $0.18-0.24$ & 2.597 & 0.915 & 7.375 & 0.073 & 3.703 & 0.621 & 22.072 & 0.151 & 3.141 & 0.945 & 10.442 & 0.062 & 6.748 & 0.628 & 72.518 & 0.115 \\
\hline $0.14-0.18$ & 1.493 & 0.88 & 2.533 & 0.137 & 0.845 & 0.383 & 1.866 & 0.677 & 1.795 & 0.984 & 3.275 & 0.056 & 1.124 & 0.396 & 3.193 & 0.827 \\
\hline$<0.14$ & 2.272 & 1.674 & 3.084 & $<0.001$ & 1.39 & 0.907 & 2.129 & 0.131 & 2.409 & 1.686 & 3.442 & $<0.001$ & 1.662 & 0.959 & 2.879 & 0.07 \\
\hline \multicolumn{17}{|l|}{ PSA (ng/ml) } \\
\hline$<4$ & - & - & - & - & - & - & - & - & - & - & - & - & - & - & - & - \\
\hline $4-10$ & 3.755 & 1.062 & 13.277 & 0.04 & 0.967 & 0.225 & 4.153 & 0.964 & 4.071 & 0.91 & 18.21 & 0.066 & 0.802 & 0.134 & 4.802 & 0.809 \\
\hline $10-20$ & 2.608 & 1.379 & 4.932 & 0.003 & 0.563 & 0.186 & 1.708 & 0.31 & 2.847 & 1.343 & 6.035 & 0.006 & 0.62 & 0.18 & 2.14 & 0.45 \\
\hline$\geq 20$ & 3.154 & 2.03 & 4.9 & $<0.001$ & 0.208 & 0.045 & 1.062 & 0.051 & 3.585 & 2.147 & 5.987 & $<0.001$ & 0.333 & 0.072 & 1.54 & 0.159 \\
\hline
\end{tabular}

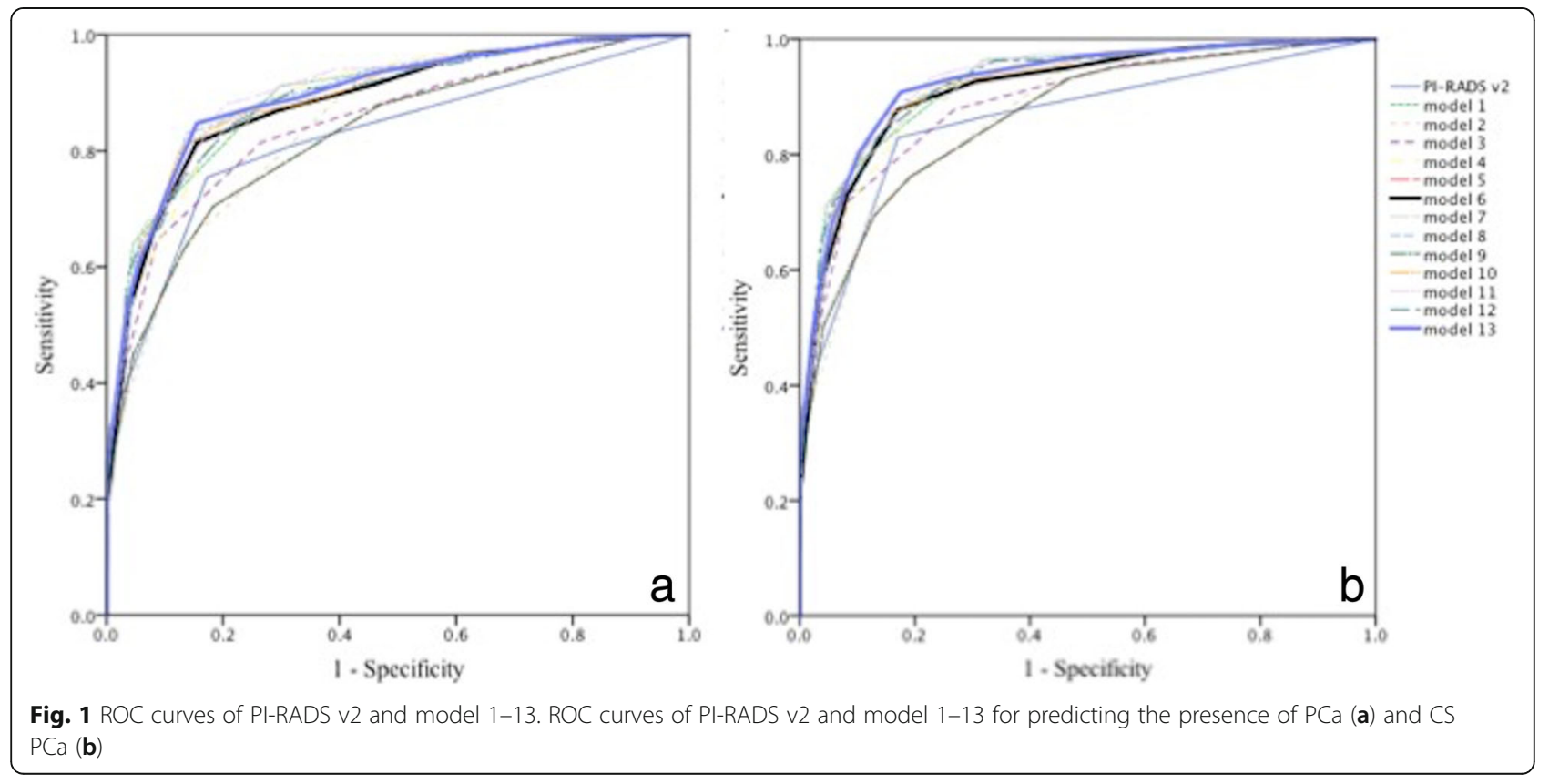


Table 3 The characteristic of differernt ROC curves of model PI-RADS v2 and model 1 to 13 in diagnosing PCa and CS PCa

\begin{tabular}{|c|c|c|c|c|c|c|c|c|c|c|c|c|c|c|}
\hline \multirow{3}{*}{$\begin{array}{l}\text { Test } \\
\text { Result } \\
\text { Variable(s) } \\
\end{array}$} & \multirow{2}{*}{\multicolumn{2}{|c|}{ Area }} & \multicolumn{4}{|c|}{ Asymptotic 95\% Confidence Interval } & \multirow{2}{*}{\multicolumn{2}{|c|}{ sensitivity }} & \multirow{2}{*}{\multicolumn{2}{|c|}{ specificity }} & \multirow{2}{*}{\multicolumn{2}{|c|}{ PPV }} & \multirow{2}{*}{\multicolumn{2}{|c|}{ NPV }} \\
\hline & & & \multicolumn{2}{|c|}{ Lower Bound } & \multicolumn{2}{|c|}{ Upper Bound } & & & & & & & & \\
\hline & Pca & CS PCa & PCa & CS PCa & PCa & CS PCa & Pca & CS PCa & PCa & CS PCa & PCa & CS PCa & PCa & CS PCa \\
\hline PIRADS V2 & 0.821 & 0.86 & 0.777 & 0.82 & 0.866 & 0.901 & 0.758 & 0.834 & 0.828 & 0.83 & 0.822 & 0.805 & 0.766 & 0.856 \\
\hline model 1 & 0.891 & 0.922 & 0.858 & 0.894 & 0.925 & 0.95 & 0.716 & 0.791 & 0.891 & 0.892 & 0.873 & 0.86 & 0.749 & 0.836 \\
\hline model 2 & 0.849 & 0.874 & 0.81 & 0.839 & 0.887 & 0.909 & 0.705 & 0.767 & 0.793 & 0.794 & 0.782 & 0.758 & 0.719 & 0.802 \\
\hline model 3 & 0.847 & 0.889 & 0.807 & 0.854 & 0.887 & 0.923 & 0.814 & 0.877 & 0.736 & 0.732 & 0.764 & 0.733 & 0.79 & 0.877 \\
\hline model 4 & 0.891 & 0.916 & 0.858 & 0.887 & 0.924 & 0.945 & 0.918 & 0.914 & 0.649 & 0.778 & 0.734 & 0.776 & 0.883 & 0.915 \\
\hline model 5 & 0.877 & 0.91 & 0.841 & 0.88 & 0.912 & 0.94 & 0.847 & 0.773 & 0.753 & 0.881 & 0.783 & 0.846 & 0.824 & 0.822 \\
\hline model 6 & 0.884 & 0.913 & 0.849 & 0.882 & 0.918 & 0.943 & 0.814 & 0.877 & 0.845 & 0.83 & 0.847 & 0.813 & 0.812 & 0.89 \\
\hline model 7 & 0.892 & 0.922 & 0.859 & 0.894 & 0.925 & 0.95 & 0.836 & 0.896 & 0.799 & 0.784 & 0.814 & 0.777 & 0.822 & 0.899 \\
\hline model 8 & 0.896 & 0.924 & 0.863 & 0.896 & 0.929 & 0.951 & 0.842 & 0.89 & 0.822 & 0.84 & 0.832 & 0.824 & 0.831 & 0.901 \\
\hline model 9 & 0.886 & 0.918 & 0.852 & 0.888 & 0.92 & 0.947 & 0.842 & 0.877 & 0.78 & 0.804 & 0.798 & 0.79 & 0.823 & 0.886 \\
\hline model 10 & 0.892 & 0.921 & 0.858 & 0.893 & 0.925 & 0.95 & 0.836 & 0.865 & 0.821 & 0.856 & 0.832 & 0.834 & 0.847 & 0.896 \\
\hline model 11 & 0.898 & 0.926 & 0.866 & 0.899 & 0.931 & 0.953 & 0.88 & 0.933 & 0.799 & 0.773 & 0.821 & 0.776 & 0.863 & 0.932 \\
\hline model 12 & 0.889 & 0.922 & 0.855 & 0.894 & 0.923 & 0.95 & 0.847 & 0.828 & 0.782 & 0.866 & 0.803 & 0.839 & 0.829 & 0.857 \\
\hline model 13 & 0.889 & 0.925 & 0.862 & 0.898 & 0.928 & 0.953 & 0.847 & 0.908 & 0.845 & 0.825 & 0.852 & 0.813 & 0.84 & 0.813 \\
\hline
\end{tabular}

specificity, PPV and NPV of 0.908 (148/163), 0.825 (160/ $194), 0.813$ (148/182) and $0.914(160 / 175)$, respectively.

The scores of model 6 and PI-RADS v2 are presented in Fig. 2. The score of model 6 increased as the GS increased. The mean scores of different four-tiered groupings exhibited significant differences $(p<0.001$, Table 4$)$. The mean values and 95\% confidence intervals for the means of GS groups 1-4 were 10.20 (9.63-10.40), 12.03 (11.19-12.87), 14.12 (13.6014.64) and 15.44 (15.09-15.79). The scores among GS $8-10$ had no significant differences $(p=0.055)$.

\section{Discussion}

Our study revealed that PI-RADS v2, PSA, f/t PSA and PSAD were significant predictors of PCa and CS PCa. In addition, our study established a new PCa accumulating model, which may assess the risk of PCa noninvasively. However, the scores for model 6 had no significant difference among GS 8 to 10 .

In accordance with previous studies, PI-RADS v2 itself is efficient in diagnosing PCa. When the PI-RADS v2 score $\geq 4$ was supposed to be positive, it had a sensitivity of $85-88 \%$ and a specificity of $55-71 \%$ for PCa [23].

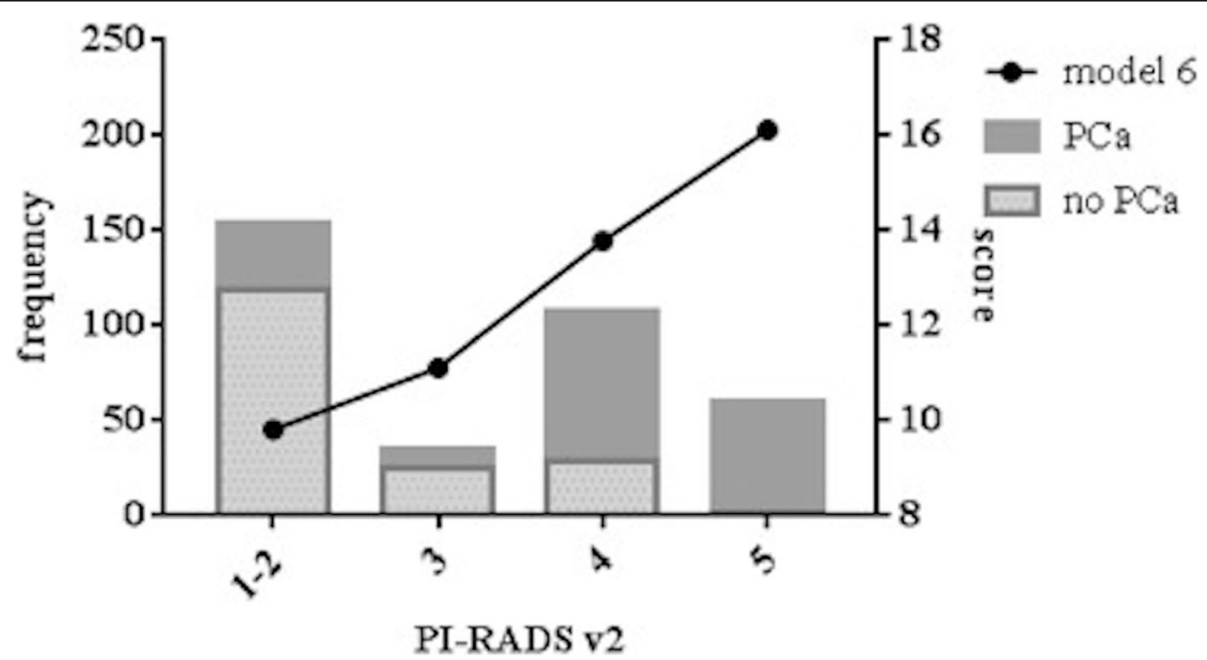

Fig. 2 Relationship between model 6 and PI-RADS v2. Tendency of model 6 in pace with PI-RADS v2 and the distributions of PCa among PIRADS v2 scores 
Table 4 Scores of the model 6 in four-tiered Gleason score groupings

\begin{tabular}{|c|c|c|c|c|c|c|c|c|}
\hline \multirow[t]{2}{*}{ Gleason score } & \multirow[t]{2}{*}{$\mathrm{N}$} & \multirow[t]{2}{*}{ Mean } & \multirow{2}{*}{$\begin{array}{l}\text { Std. } \\
\text { Deviation }\end{array}$} & \multirow{2}{*}{$\begin{array}{l}\text { Std. } \\
\text { Error }\end{array}$} & \multicolumn{2}{|c|}{ 95\% Confidence Interval for Mean } & \multirow[t]{2}{*}{ Minimum } & \multirow[t]{2}{*}{ Maximum } \\
\hline & & & & & Lower Bound & Upper Bound & & \\
\hline 0 (group 1) & 174 & 10.02 & 2.59 & 0.2 & 9.63 & 10.4 & 5 & 16 \\
\hline 6 (group 2) & 34 & 12.03 & 2.42 & 0.41 & 11.19 & 12.87 & 7 & 17 \\
\hline 7 (group 3) & 74 & 14.12 & 2.24 & 0.26 & 13.6 & 14.64 & 6 & 17 \\
\hline 8-10 (group 4) & 75 & 15.44 & 1.51 & 0.17 & 15.09 & 15.79 & 11 & 17 \\
\hline Total & 357 & 12.2 & 3.26 & 0.17 & 11.86 & 12.54 & 5 & 17 \\
\hline
\end{tabular}

However, because its specificity was low and its NPV was unstable [5], some people were misdiagnosed. In previous studies, a PI-RADS v2 score of 1-2 rarely yielded PCa, while the connection between PI-RADS v2 score 3 and the presence of PCa was uncertain [24, 25]. Our study found that the detection rates of $\mathrm{PCa}$ using PI-RADS v2 scores of $1-2,3$, and $4-5$ were $22.7 \%$ (35/ 154), $28.6 \%(10 / 35)$ and $82.1 \%(138 / 168)$, respectively. In other words, 45 patients were missed when PI-RADS v2 score $\geq 4$ was supposed to be positive, and 30 were over-diagnosed.

Serum PSA is the most common index to detect and decide the absence or presence of $\mathrm{PCa}$ and to monitor its aggressiveness [26]. In clinical practice, PSA is a reference to determine whether to perform a biopsy. However, the specificity of PSA in PCa detection is unsatisfactory. For people with PSA between 4 and 10 $\mathrm{ng} / \mathrm{mL}$, only a quarter suffered PCa [27]. As a result, many men without cancer underwent unnecessary biopsies, PCa cases were often detected, and CS PCa cases were sometimes missed [28, 29]. When PSA > $20 \mathrm{ng} / \mathrm{ml}$, up to $84.2 \%(80 / 95)$ suffered from PCa in our study, and among these, $11.3 \%$ (9/80) were excluded from PCa in mpMRI. To improve the diagnostic accuracy, other serum indexes, such as $\mathrm{f} / \mathrm{t}$ PSA and PSAD, are often used to assist PCa diagnosis. The $\mathrm{f} / \mathrm{t}$ PSA combination increased the specificity of early detection compared to PSA alone [30]. Specificity could be improved threefold with stable sensitivity by incorporating f/t PSA into predictive factors [31]. The cut-off point of 0.18 has been widely used in clinical applications [16]. Few studies have explored the value of PSAD [32, 33]. In recent studies, patients with a PSAD of $<0.15 \mathrm{ng} / \mathrm{mL} / \mathrm{mL}$ may avoid unnecessary biopsies [11]. Furthermore, PSAD had a positive influence on CS PCa diagnosis [33]. Previous studies reported the relationship between PI-RDAS v2 and PSA $[11,34]$. According to their results, PSA and $\mathrm{f} / \mathrm{t}$ PSA were not independent factors in logistic regression analysis. PSAD, as an independent index, was combined with PI-RADS v2 to explain its function in PCa detection. In our study, in patients with PI-RADS v2 scores $\geq 4$ and/or PSAD $\geq 0.15 / \mathrm{ng} / \mathrm{ml} / \mathrm{ml}$, the sensitivity, specificity, PPV and NPV were 61.4, 88.9, 95.6 and 36.8\%, respectively. It showed high PPV when it adhered to these criteria, with low NPV. Collectively, it is worth trying to coordinate PI-RADS with PSA, f/t PSA and PSAD for predicting $\mathrm{PCa}$.

Our study emphasizes the importance of comprehensively assessing both the imaging and clinical data of patients. Imitating PI-RADS v2, this study adopts an accumulating model and, to our knowledge, is the first study to use an accumulating system in diagnosing $\mathrm{PCa}$. The study stratified all variables into several levels and put weight on each level with different scores to simplify and quantify the assessment of PCa. When the method of quantifying and accumulating the data is used, the subject and individual experience effects decrease. Building an accumulating system that is suitable and that can be applied in clinical settings may be meaningful. For convenient clinical application, model 6 is recommended, and model 13 is recommended to diagnose PCa more accurately. Model 6 shows satisfactory diagnostic capacity and is convenient, which not only enhances the accuracy of the diagnosis of PCa and CS PCa but also quantifies the process of assessing $\mathrm{PCa}$. Although PSA and f/t PSA were rejected in logistic regression, they are helpful in increasing the specificity and sensitivity in the diagnosis of PCa and CS PC (Fig. 1). Thus, PSA and $\mathrm{f} / \mathrm{t}$ PSA were included in the predictive model whether they were independent predictors or not. We also found that when the effects of PI-RADS v2 and PSAD were emphasized, the efficiencies of PSA and $f / t$ PSA decreased (models 8 to 10), which may result from the level of PSAD has a strong relation to the level of PSA $(K=0.626)$ and $\mathrm{f} / \mathrm{t}$ PSA $(\mathrm{K}=0.422)$.

The head-to-head-comparison between each category showed the odds radios of each level. In univariate logistic regression analyses, higher levels of each variable had higher approximate risks of PCa when $p<0.05$ indicated statistical significance. The $95 \%$ confidence intervals of level 2 of PSAD, f/t PSA and PSA were too broad to evaluate the risk, possibly because it was an unclear zone for detecting PCa and CS PCa and needed more specific classifications.

Further, the scores of model 6 are related to GS. Previous studies have reported that PI-RADS v2 had no significant correction with GS distribution [35], and to our knowledge, there is no research reporting the 
relationship between GS and the combination of PI-RADS v2 and PSA. In our study, the scores for model 6 increased in the four-tiered groupings. The scores for GS 8 to 10 had no significant differences. This may be because there were not enough cases of these GS to analyse, and the stratification criterion of the study does not consider dividing data that are far away from the range of normal values. In this study, it did not classify GS 7 into $3+4$ and $4+3$ because having few cases would lead to result shifting. However, the study is still valuable, as the prognoses of GS at 8-10 can be classified into the same group [17]. This result may be helpful in assessing aggressiveness in non-invasive testing.

In all, our study describes a new way to predict the presence of PCa using an intuitive and objective score to balance the difference in efficiency among all parameters. When the case is negative according to PI-RADS v2, our study gives a simple reference regarding whether to perform a biopsy on the basis of the level of PSA, $f / t$ PSA and PSAD in clinical work.

However, the study has some limitations. First, our study is retrospective, and patient selection bias exists. There was no case of a score of 1 in PI-RADS v2 because the patients' mean age in this study was higher than 60. The signal we observed on T2WI was not homogeneous in these elderly patients. We paid no attention to the role of extreme values of clinical data. At our institution, the test would not provide an explicit figure if the PSA level was greater than $1000 \mathrm{ng} / \mathrm{mL}$, and we defined the f/t PSA as 0.001 in these situations. However, this would not upgrade the f/t PSA group. Further studies may include more clinical data, such as age, race and family history. It would be better to stratify PSA along with age to accumulate scores [36, 37].

\section{Conclusions}

Our study takes advantage of PSA, f/t PSA and PSAD by combining these variables with PI-RADS v2 to establish a new accumulating model that increases the accuracy of the primary diagnosis of $\mathrm{PCa}$ and may be helpful in the clinical decision to perform a biopsy.

\section{Abbreviations \\ CS PCa: Clinically significant prostate cancer; DWI: Diffusion weighted imaging; f/t PSA: Free/total PSA ratio; GS: Gleason score; MR: Magnetic resonance; PCa: Prostate cancer; PI-RADS v2: Prostate Imaging-Reporting and} Data System Version 2; PSA: Prostate specific antigen; PSAD: PSA density

Acknowledgements

Not applicable.

\section{Funding}

Not applicable.

\section{Availability of data and materials}

The datasets used and/or analysed during the current study are available from the corresponding author on reasonable request.

\section{Authors' contributions}

LYF conceived of the study, participated in its design and coordination and helped to draft the manuscript; ZQ participated in its design and coordination and helped to draft the manuscript; YWG and Chen HY participated in the data processing. Chen JY and XCC collected clinical and imaging data. All authors have read and approved the final version of the manuscript and agree with the order of presentation of the authors.

\section{Ethics approval and consent to participate}

All procedures performed in studies involving human participants were in accordance with the ethical standards of the institutional and/or national research committee and with the 1964 Helsinki declaration and its later amendments or comparable ethical standards. The requirement for informed consent was waived by the institutional review board.

\section{Consent for publication}

All the authors have consented to the publication of this manuscript.

\section{Competing interests}

The authors who have taken part in this study have declared that they do not have any conflict of interest with respect to this manuscript.

\section{Publisher's Note}

Springer Nature remains neutral with regard to jurisdictional claims in published maps and institutional affiliations.

\section{Author details}

'Department of Radiology, Second Affiliated Hospital, School of Medicine, Zhejiang University, 88 Jie-Fang Road, Zhejiang 310009, Hangzhou, China. ${ }^{2}$ Department of Radiology, Yangming Affiliated Hospital, School of Medicine, Ningbo University, Yuyao 315400, Zhejiang, China. ${ }^{3}$ Department of Urology, Second Affiliated Hospital, School of Medicine, Zhejiang University, Hangzhou 310000, Zhejiang, China.

Received: 15 October 2018 Accepted: 16 April 2019

Published online: 23 May 2019

\section{References}

1. Mottet N, Bellmunt J, Bolla M, et al. EAU-ESTRO-SIOG guidelines on prostate Cancer. Part 1: screening, diagnosis, and local treatment with curative intent. Eur Urol. 2017;71(4):618-29.

2. Zhang K, Bangma CH, Roobol MJ. Prostate cancer screening in Europe and Asia. Asian J Urol. 2017;4(2):86-95.

3. Rosenkrantz AB, Babb JS, Taneja SS, Ream JM. Proposed adjustments to PIRADS version 2 decision rules: impact on prostate Cancer detection. Radiology. 2017;283(1):119-29.

4. PI-RADS v2. https://www.acr.org/-/media/ACR/Files/RADS/Pi-RADS/PIRADSV2.pdf. Accessed 10 Jan 2019.

5. de Rooij M, Hamoen EH, Futterer JJ, Barentsz JO, Rovers MM. Accuracy of multiparametric MRI for prostate cancer detection: a meta-analysis. AJR Am J Roentgenol. 2014;202(2):343-51

6. Chou R, Croswell JM, Dana T, et al. Screening for prostate cancer: a review of the evidence for the U.S. preventive services task force. Ann Intern Med. 2011;155(11):762-71.

7. Hernandez C, Morote J, Minana B, Cozar JM. The role of prostate-specific antigen in light of new scientific evidence. Actas Urol Esp. 2013;37(6):324-9.

8. Hansen NL, Barrett T, Koo B, et al. The influence of prostate-specific antigen density on positive and negative predictive values of multiparametric magnetic resonance imaging to detect Gleason score 7-10 prostate cancer in a repeat biopsy setting. BJU Int. 2017;119(5):724-30.

9. Milkovic B, Dzamic Z, Pejcic T, et al. Evaluation of free-to-total prostate specific antigen (F/T PSA), prostate specific antigen density (PSAD) and (F/ T)/PSAD sensitivity on reduction of unnecessary prostate biopsies for patients with PSA in gray zone. Ann Ital Chir. 2014;85(5):448-53.

10. Washino S, Okochi T, Saito $K$, et al. Combination of prostate imaging reporting and data system (PI-RADS) score and prostate-specific antigen (PSA) density predicts biopsy outcome in prostate biopsy naive patients. BJU Int. 2017:119(2):225-33.

11. Nordstrom T, Akre O, Aly M, Gronberg H, Eklund M. Prostate-specific antigen (PSA) density in the diagnostic algorithm of prostate cancer. Prostate Cancer Prostatic Dis. 2018;21(1):57-63. 
12. Kasivisvanathan $\mathrm{V}$, Dufour $\mathrm{R}$, Moore CM, et al. Transperineal magnetic resonance image targeted prostate biopsy versus transperineal template prostate biopsy in the detection of clinically significant prostate cancer. J Urol. 2013:189(3):860-6.

13. Greene $\mathrm{KL}$, Albertsen $\mathrm{PC}$, Babaian $\mathrm{RJ}$, et al. Prostate specific antigen best practice statement: 2009 update. J Urol. 2013;189(1 Suppl):S2-s11.

14. Magheli A, Hinz S, Hege C, et al. Prostate specific antigen density to predict prostate cancer upgrading in a contemporary radical prostatectomy series: a single center experience. J Urol. 2010;183(1):126-31.

15. Kundu SD, Roehl KA, Yu X, Antenor JA, Suarez BK, Catalona WJ. Prostate specific antigen density correlates with features of prostate cancer aggressiveness. J Urol. 2007;177(2):505-9.

16. Finne $P$, Auvinen $A$, Maattanen $L$, et al. Diagnostic value of free prostatespecific antigen among men with a prostate-specific antigen level of $<3.0$ microg per liter. Eur Urol. 2008;54(2):362-70.

17. Gleason DF, Mellinger GT. Prediction of prognosis for prostatic adenocarcinoma by combined histological grading and clinical staging. J Urol. 2017;197(2s):S134-s139.

18. Bill-Axelson A, Garmo H, Holmberg L, et al. Long-term distress after radical prostatectomy versus watchful waiting in prostate cancer: a longitudinal study from the Scandinavian prostate Cancer Group-4 randomized clinical trial. Eur Urol. 2013;64(6):920-8.

19. Epstein Jl, Zelefsky MJ, Sjoberg DD, et al. A contemporary prostate Cancer grading system: a validated alternative to the Gleason score. Eur Urol. 2016; 69(3):428-35.

20. D'Amico AV, Whittington R, Malkowicz SB, et al. Biochemical outcome after radical prostatectomy, external beam radiation therapy, or interstitial radiation therapy for clinically localized prostate cancer. Jama. 1998;280(11):969-74

21. Epstein Jl, Feng Z, Trock BJ, Pierorazio PM. Upgrading and downgrading of prostate cancer from biopsy to radical prostatectomy: incidence and predictive factors using the modified Gleason grading system and factoring in tertiary grades. Eur Urol. 2012;61(5):1019-24.

22. Knuchel R. Gleason score 6 - prostate Cancer or benign variant? Oncology research and treatment. 2015;38(12):629-32.

23. Barentsz JO, Weinreb JC, Verma S, et al. Synopsis of the PI-RADS V2 guidelines for multiparametric prostate magnetic resonance imaging and recommendations for use. Eur Urol. 2016;69(1):41-9.

24. Brizmohun Appayya M, Sidhu HS, Dikaios N, et al. Characterizing indeterminate (Likert-score 3/5) peripheral zone prostate lesions with PSA density, PI-RADS scoring and qualitative descriptors on multiparametric MRI. Br J Radiol. 2018;91(1083):20170645.

25. Thai JN, Narayanan HA, George AK, et al. Validation of PI-RADS version 2 in transition zone lesions for the detection of prostate Cancer. Radiology. 2018; 288(2):485-91.

26. Polascik TJ, Oesterling JE, Partin AW. Prostate specific antigen: a decade of discovery--what we have learned and where we are going. J Urol. 1999; 162(2):293-306.

27. Eide IA, Angelsen A. Prostate-specific antigen. Tidsskrift for den Norske lageforening : tidsskrift for praktisk medicin, ny rakke. 2000;120(21): 2528-31.

28. Abraham NE, Mendhiratta N, Taneja SS. Patterns of repeat prostate biopsy in contemporary clinical practice. J Urol. 2015;193(4):1178-84.

29. Ahmed HU, El-Shater Bosaily A, Brown LC, et al. Diagnostic accuracy of multiparametric MRI and TRUS biopsy in prostate cancer (PROMIS): a paired validating confirmatory study. Lancet (London, England). 2017;389(10071):815-22.

30. Catalona WJ, Southwick PC, Slawin KM, et al. Comparison of percent free PSA, PSA density, and age-specific PSA cutoffs for prostate cancer detection and staging. Urology. 2000;56(2):255-60.

31. Filella X, Alcover J, Molina R, Carretero P, Ballesta AM. Clinical usefulness of PSA in the early diagnosis of prostate cancer. Vol 111998.

32. Miele M. Percent free PSA as an additional measure in a prostate cancer screen. Vol 142001.

33. Alberts AR, Roobol MJ, Drost FH, et al. Risk-stratification based on magnetic resonance imaging and prostate-specific antigen density may reduce unnecessary follow-up biopsy procedures in men on active surveillance for low-risk prostate cancer. BJU Int. 2017;120(4):511-9.

34. Scialpi M, Martorana E, Aisa MC, Rondoni V, D'Andrea A, Bianchi G. Score 3 prostate lesions: a gray zone for PI-RADS v2. Turk J Urol. 2017;43(3):237-40.

35. Slaoui $H$, Neuzillet $Y$, Ghoneim $T$, et al. Gleason score within prostate abnormal areas defined by multiparametric magnetic resonance imaging did not vary according to the PIRADS score. Urol Int. 2017;99(2):156-61.
36. Savblom C, Malm J, Giwercman A, Nilsson JA, Berglund G, Lilja H. Blood levels of free-PSA but not complex-PSA significantly correlates to prostate release of PSA in semen in young men, while blood levels of complex-PSA, but not free-PSA increase with age. Prostate. 2005;65(1):66-72.

37. Liu ZY, Sun YH, Xu CL, Gao X, Zhang LM, Ren SC. Age-specific PSA reference ranges in Chinese men without prostate cancer. Asian journal of andrology. 2009;11(1):100-3.

\section{Ready to submit your research? Choose BMC and benefit from:}

- fast, convenient online submission

- thorough peer review by experienced researchers in your field

- rapid publication on acceptance

- support for research data, including large and complex data types

- gold Open Access which fosters wider collaboration and increased citations

- maximum visibility for your research: over $100 \mathrm{M}$ website views per year

At BMC, research is always in progress.

Learn more biomedcentral.com/submissions 